\title{
THE SEISMIC PERFORMANCE OF ENERGY ABSORBING DAMPERS IN BUILDING STRUCTURES
}

\author{
D.E. Key* \\ Presented to the Third South Pacific Regional Conference on \\ Earthquake Engineering, Wellington, May 1983.
}

SYNOPSIS:

By separating the stiff shear walls of the structural core of a building from the more flexible column/beam/slab structure two independent structures with markedly different dynamic properties are formed. By introducing damping elements between the two, energy is absorbed during earthquakes, giving considerably improved response characteristics.

A ten storey office structure incorporating dampers in this fashion is studied by time history analysis, using five simulated earthquakes. Dampers are provided at each floor level. The analysis treats the damping as hysteretic, based on the type described by Kelly (1972).

Significant reductions in structural response are achieved by this means.

\section{INTRODUCTION:}

A structure designed to resist earthquake motion needs the capacity to dissipate energy. The inherent damping of typical structural materials is low while performing within the elastic range, so that most energy dissipation takes place in the form of inelastic material response. In a typical framed structure this is localised in the vicinity of beam to column connections.

Non-linear behaviour of the connections presents a number of problems. In the first place the large displacements involved create stability problems and involve a high level of non-structural damage. Secondly the reliability of the connections themselves is questionable. steel connections suffer from local instabilities and reinforced concrete frames are subject to diagonal tension and bond failures.

Even in the best designed structures there is an inevitable consequence of strong ground motion i.e. heavy structural and non-structural damage. In consequence the concept of an independent, replaceable, energy absorbing element is in principle an attractive one. The initial damping values of the system are increased and in a major earthquake when structural damage would normally be expected, energy dissipation would mainly take place in discrete elements with little damage taking place in the structure. The load carrying function of the structure and the energy absorbing function would thus be separated.

\section{REVIEW OF DAMPED STRUCTURES:}

Zeller (1973) describes tests on a steel building in Paris where the floors

* CEP International, Consulting Engineers, and Department of Civil Engineering, Southampton University, England were supported on visco-elastic butyl blocks. These showed an increase in the structural damping of the system from $2 \%$ to $6 \%$. The World Trade centre in New York incorporates visco-elastic sandwich elements into the support connections to 10,000 floor beams in order to reduce wind response (Anon, 1971).

Gasparini (1980) analyses the effect of introducing a visco-elastic sandwich between adjacent internal columns of a steel structure. It is shown that an increase in damping from $0.5 \%$ to $5.4 \%$ can be achieved by this means.

Skinner (1975 ref.1) proposes various configurations in which energy absorbing devices can be introduced into multi storey building structures. These are shown in Figure 1 . The objective in locating these devices is to connect points with large relative displacement and it may be necessary to produce special structural configurations in order to incorporate these devices. The structure has to be designed at the conceptual stage to incorporate the additional damping.

The study of practical mechanical systems for dampers has mainly taken place in New Zealand and Japan. Matsushita (1973) describes the use of crushable concrete blocks placed in the movement joints of a 200 metre high building. During the movement in the joint caused by an earthquake the blocks are crushed, being replaced by other blocks which fall into the gap.

Robinson (1976) describes energy absorbers based on the extrusion of lead. After extrusion the lead recrystallises very rapidly, recovering its original mechanical properties. Whilst testing shows the system to be capable of coping with a large number of earthquakes at frequencies up to $2 \mathrm{~Hz}$, satisfactory performance at higher frequencies needs to be verified. 

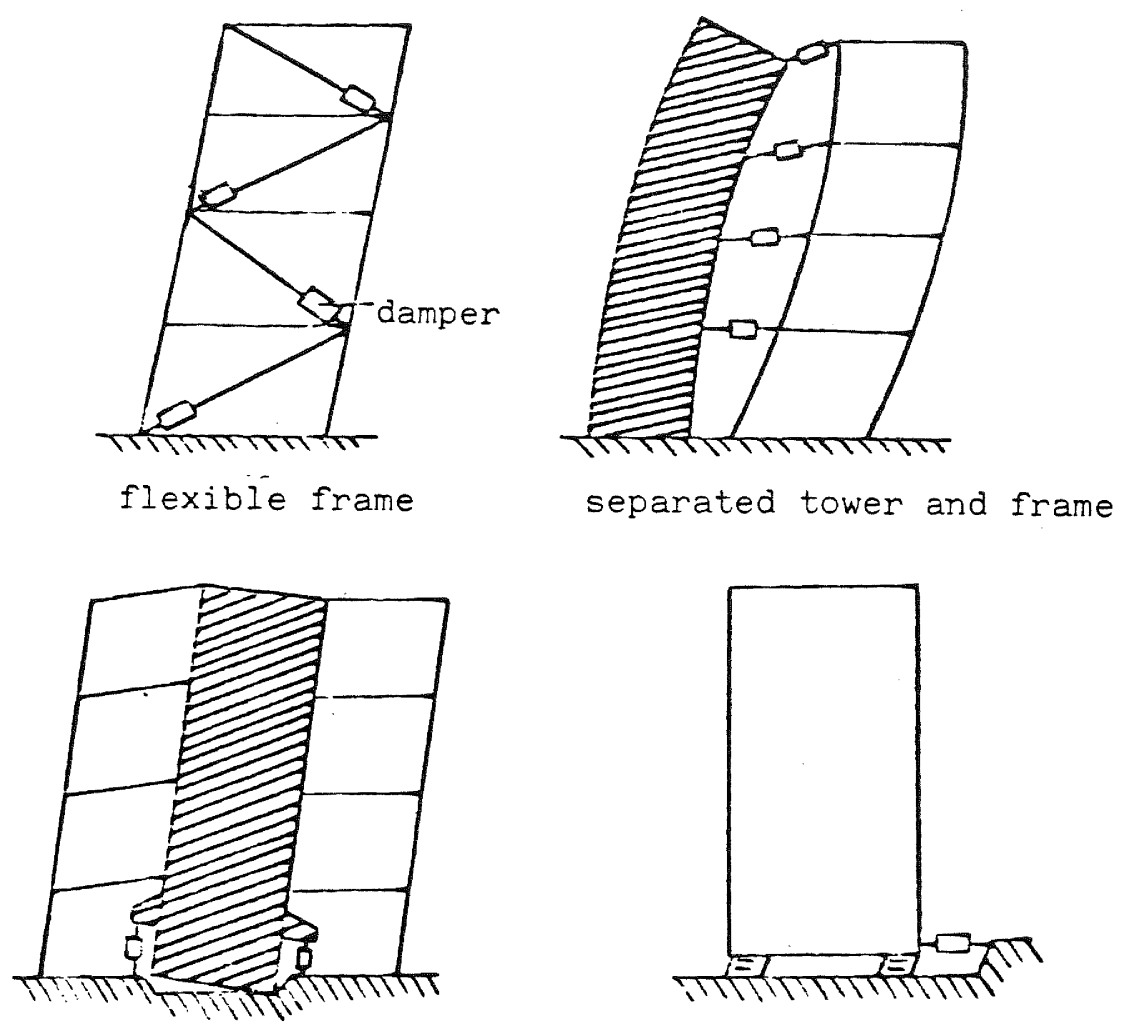

$$
\text { 'stepping! tower }
$$

lateral flexibility at base

Figure 1 Structural configurations after Skinner (1975) 
Figure 2 shows the essential elements of these devices and typical response plots.

Kelly (1972) and skinner (1975 refs. 1 \& 2) deal with a range of mechanisms based on the yielding of steel in torsion and flexure. The performance of these covers the range of practical interest, with an adequate fatigue life and an effectively time independent performance. These are shown in Figure 3.

\section{STRUCTURAL CONFIGURATION:}

Building structures can generally

be divided up, on plan, into:-

* "Usable" floor space.

* One or more core areas containing lifts, stairs, toilets and services.

\section{* External wall.}

The core and external wall may be used to provide stiff shear walls, whereas the usable floor area is generally supported on a minimum of columns and is relatively flexible in response to lateral forces. Hence for structural modelling purposes the building structure can be divided up into two elements.

* The usable floor area will comprise most of the building mass, but will be relatively flexible laterally.

* The core and external wall will comprise a small proportion of the building mass, and their stiffness laterally may range from very flexible to very stiff.

In this study the building structure is divided into two components, the $\mathrm{P}$ structure and the $Q$ structure, both illustrated in Figure 4. The $P$ structure consists of the ten storey reinforced concrete framed building. For the $Q$ structure the mass vector is taken as one tenth of the mass vector of $P$, and the stiffness vector is taken as the $P$ stiffness vector multiplied by a factor $F$.

F was varied from 9 to 30 and represents a shear wall system which could either form the core or external wall, linked to the usable floor area by discrete damping elements in the general form illustrated in Figure 4 at each floor level.

\section{ANALYSIS:}

The structure examined here utilises the hysteretic type damper which could be either of the lead extrusion type shown in Figure 2 or one of the steel devices from Figure 3. These are located in a structural joint so that forces are developed in the damper from differential displacements across the joint.

Analysis is carried out in the time domain. A bilinear hysteresis response is used to represent the damper response. The appropriate damper force vector being arrived at by iteration at each time step.
The following ranges of parameters are studied:

* Structure damping values of 0.02 , 0.05 and 0.1 .

* Peak damper force values from 0 to $3000 \mathrm{kN}$ at each floor level.

* Five earthquake acceleration records.

The earthquake records used are computer simulated accelerograms each of 20 seconds duration and scaled to a maximum acceleration of $0.3 \mathrm{~g}$. They are representative of ground motions in firm ground.

The datum structure response for each system was taken as the response of the $P$ and $Q$ structures rigidly connected. The first value of maximum damper force used in each run was a very low value and this represents a good approximation of the response of the structure with no added damping. Hence the output response values show the effect of both cutting the two sections free and of adding damping. The effect of the damping alone can be assessed by comparing response values with the zero damping values.

\section{RESULTS :}

The effect of varying the $Q$ structure stiffness has very little effect on the results, within the range examined. For this reason the values for a single $Q$ stiffness only are examined, these being regarded as typical. The response results for the structural arrangement, where the Q structure stiffness is 18.0 times the $P$ structure stiffness, are shown in Figure 5 .

Dealing firstly with the values for zero added damping, representing the effect of curring the $P$ and $Q$ structures free from each other, all the plots show a substantial increase in $\mathrm{P}$ response and comparable reduction in $Q$ (shear wall) response. This effect is not noticeably dependent on structure damping.

As the added damping is introduced the $\mathrm{P}$ response drops off very sharply and then levels off as the added damping is increased. The $Q$ structure response on the other hand shows a slow increase at first, rising slowly towards unity.

Although results are shown for base shear only, values were also obtained for roof level response. Both sets of results showed the same trends although there were minor differences.

\subsection{DESIGN IMPLICATIONS:}

A measure of the total force to be resisted by a building structure is the maximum value of base shear occurring during the earthquake. Table 1 shows a comparison for three conditions, with $\mathrm{F}=18.0$ and structure damping of 0.05 . 


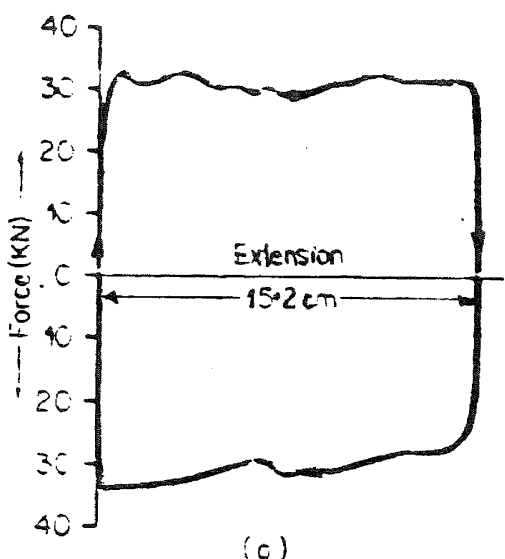

(c)

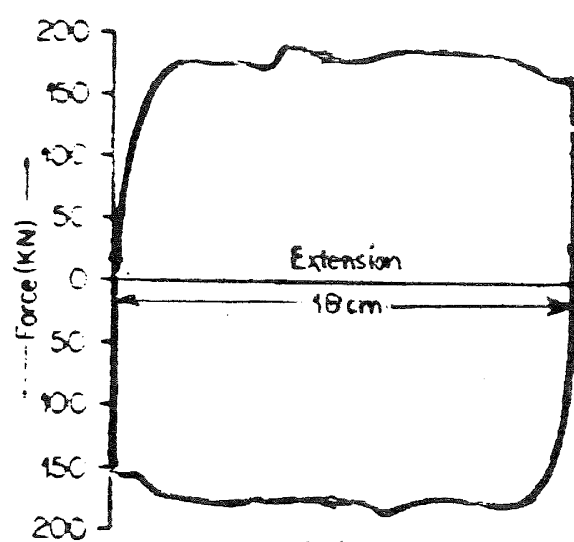

(b)

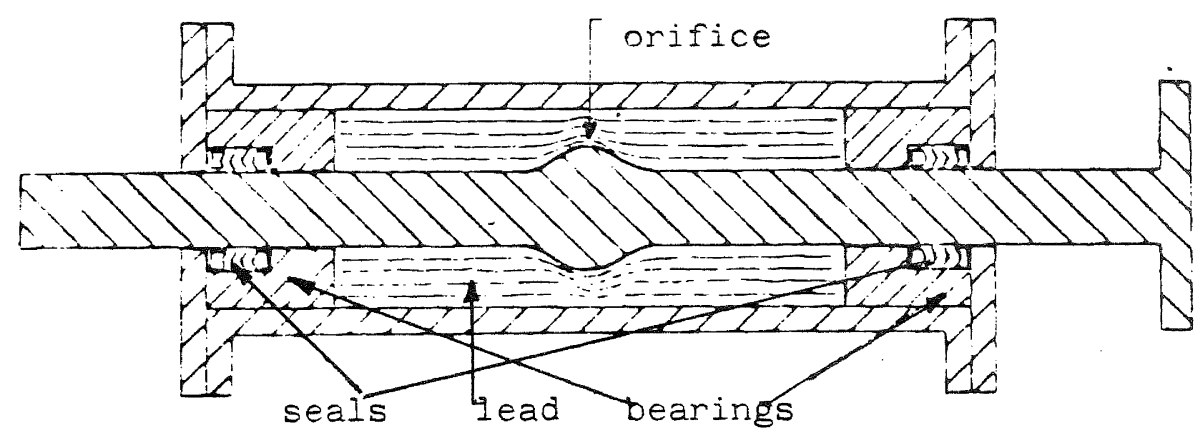

Bulged shaft absorber with typical force displacement diagram

Extrusion energy absorber after Robinson (1976)
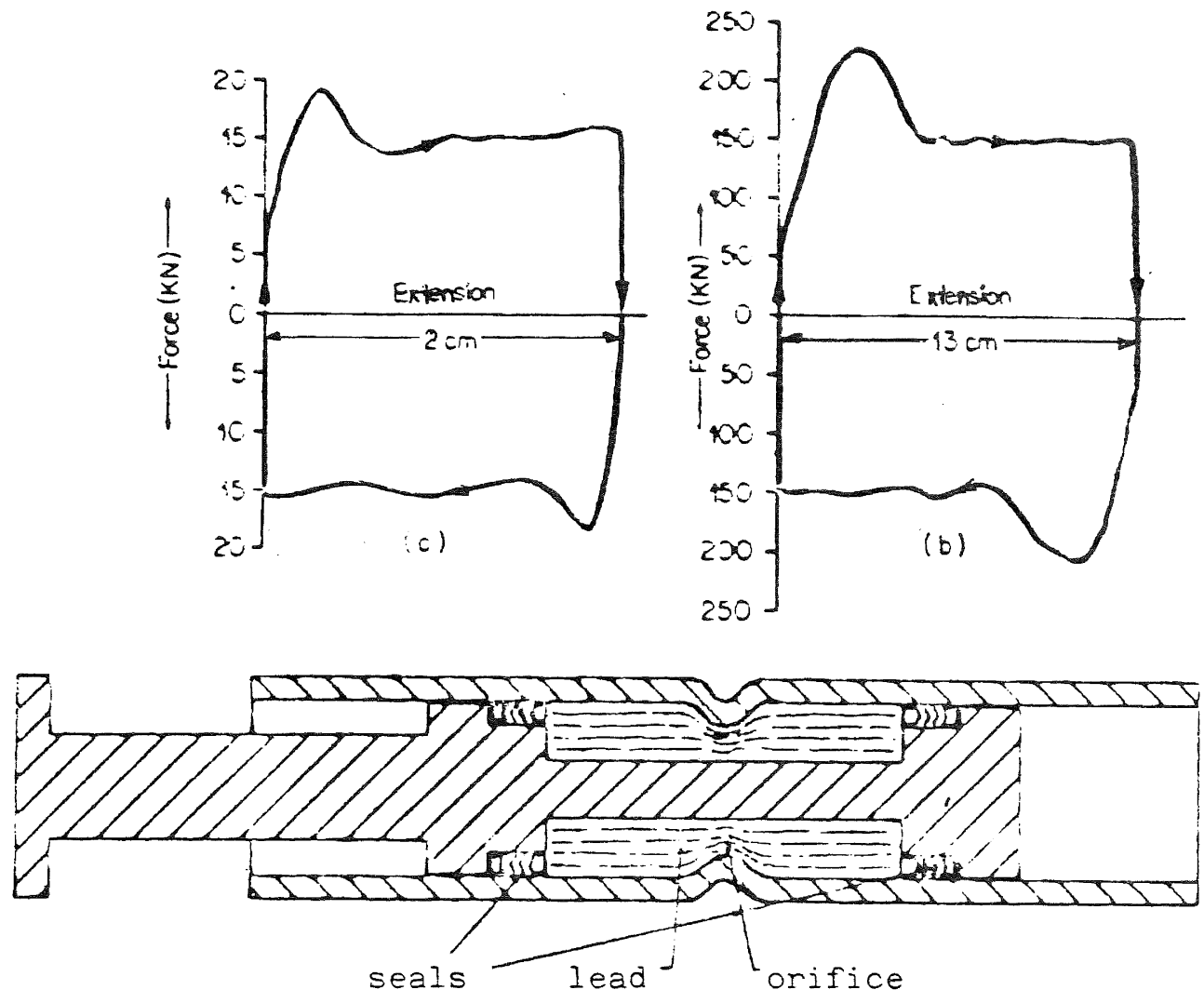

Constricted tube absorber with typical force displacement diagram 


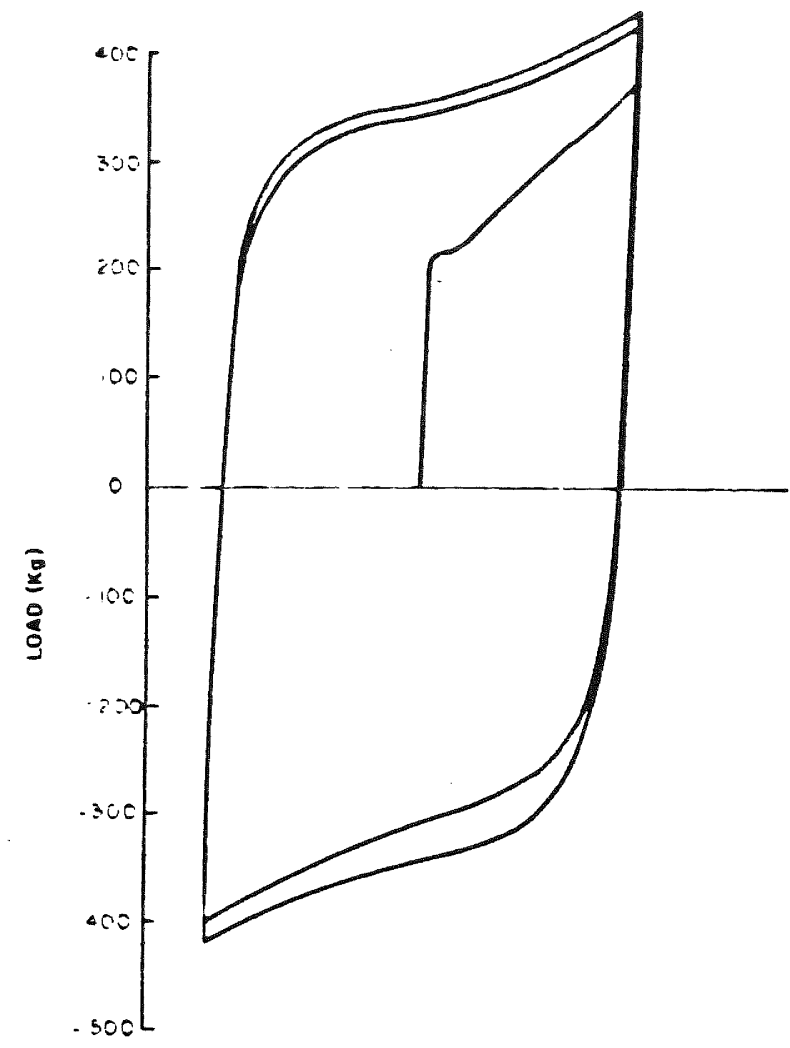

Typical hysteresis record for cyclic torsion

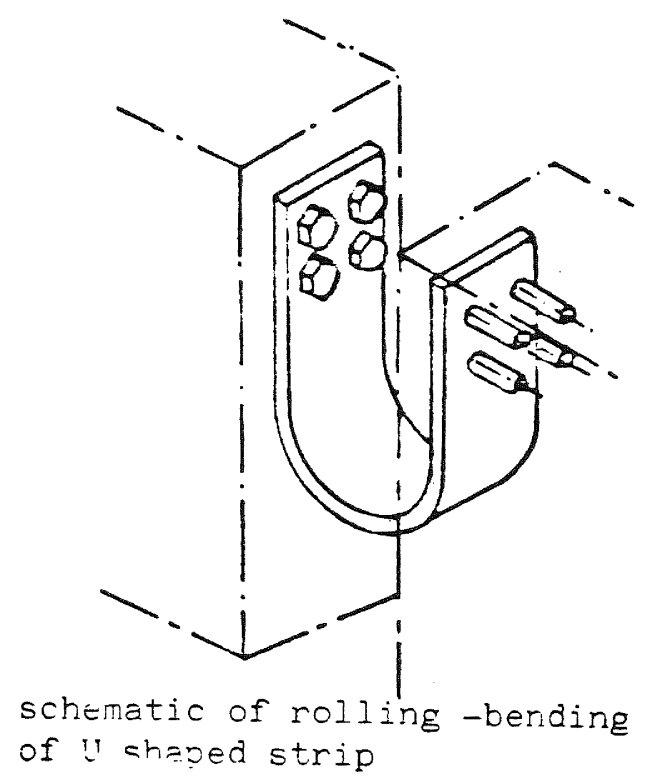

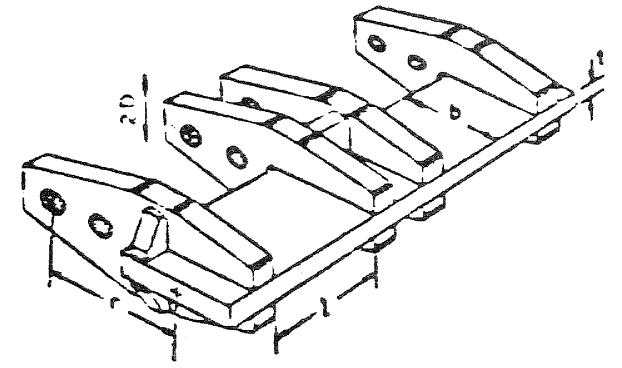

torsional beam

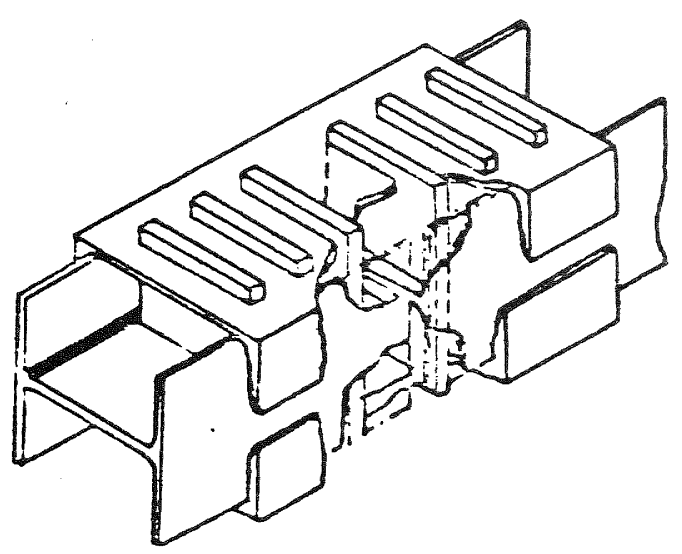

flexural energy absorbing device to fit diagonal bracing

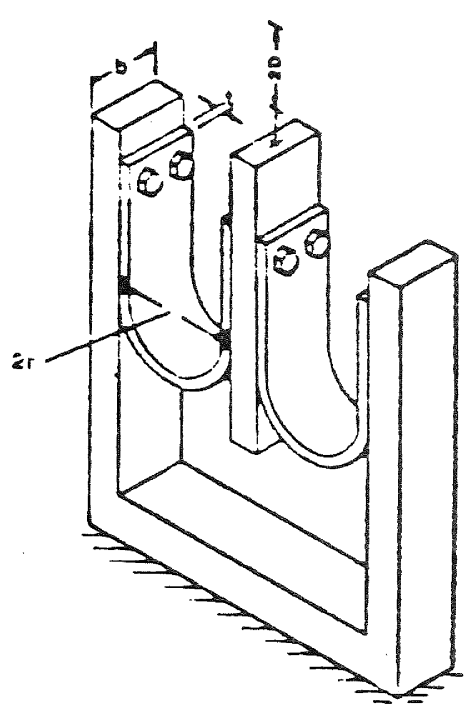

U strips

\footnotetext{
Figure $3 \quad$ Steel energy absorber after Skinner (1975), Kelly (1972)
} 


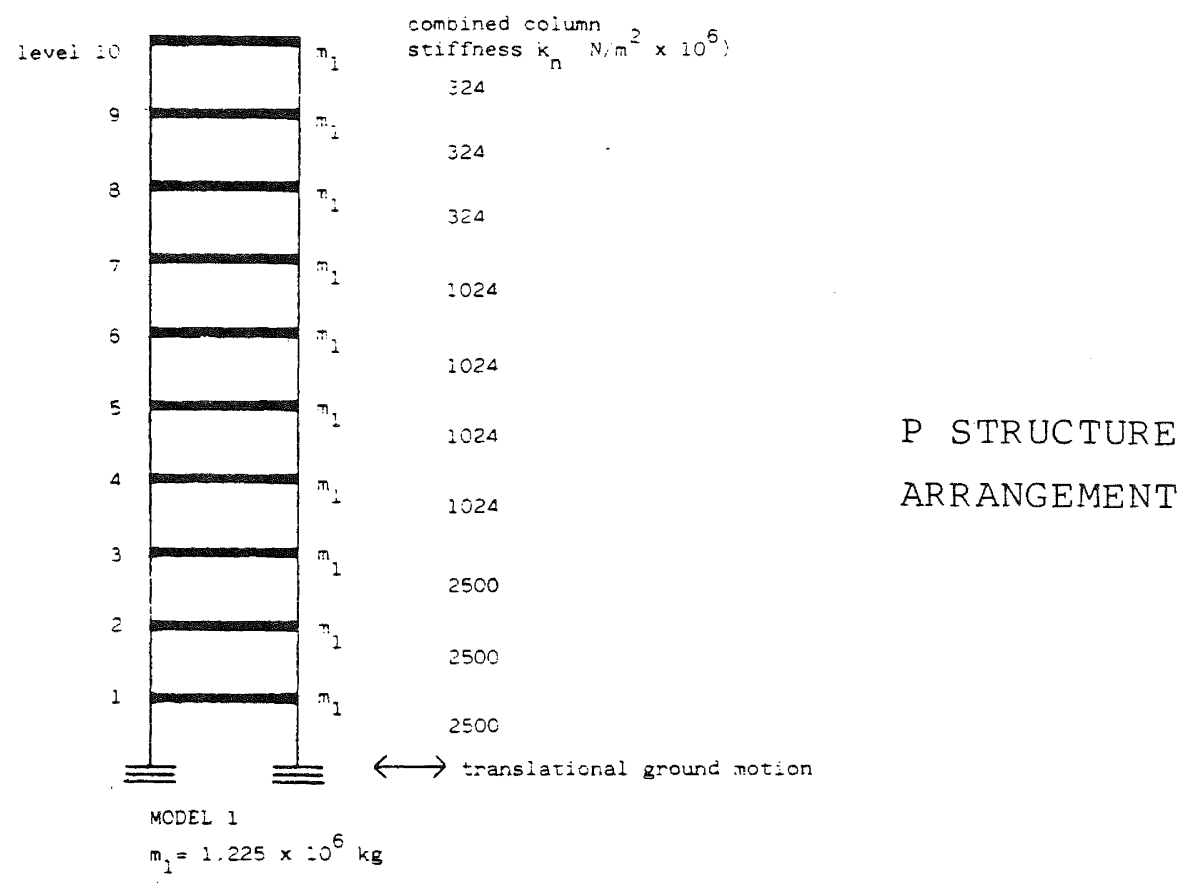

FIRS: FIVE UNDAMPED NATURAL FRQUENCIES

\begin{tabular}{|c|c|c|c|c|c|}
\hline MOLE & 1 & 2 & 3 & 4 & 5 \\
\hline racis sec & $د .66$ & 10.92 & 28.99 & 23.58 & 29.21 \\
\hline
\end{tabular}

P STRUCTURE

MODAL DATA

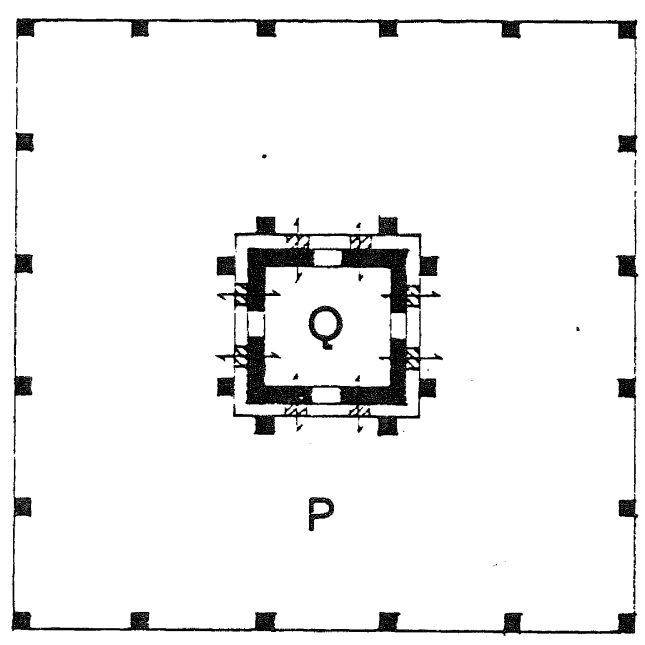

$P \& Q$ STRUCTURES

PLAN ARRANGEMENT

Unidirectional Damper

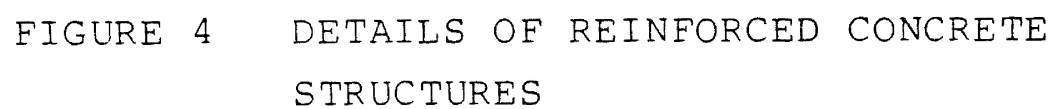




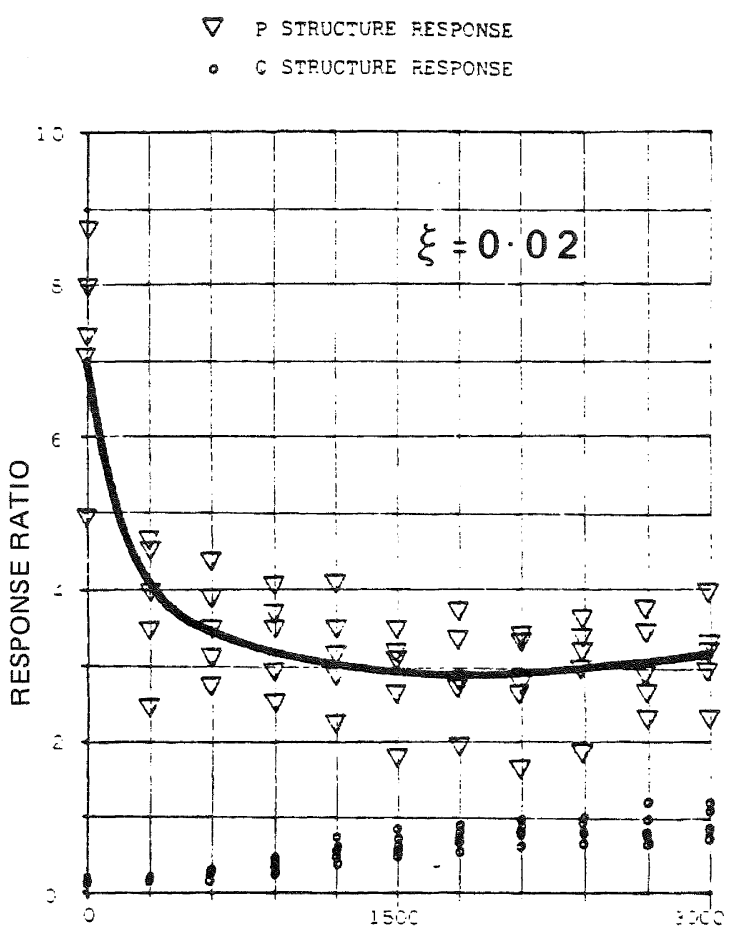

MAXIMUM DAMPER FORCE KN

$\nabla$ P STRUCTURE RESPDNSE

- o stricture response

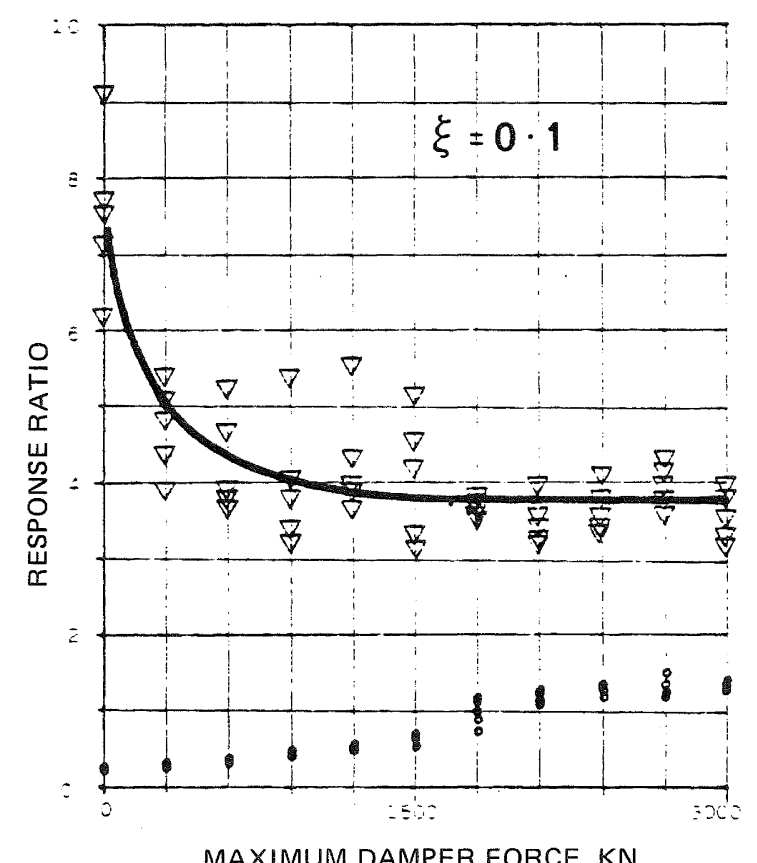

$\nabla$ P STRUCTURE RESPONSE

- Q STRUCTUEE FESPONEE

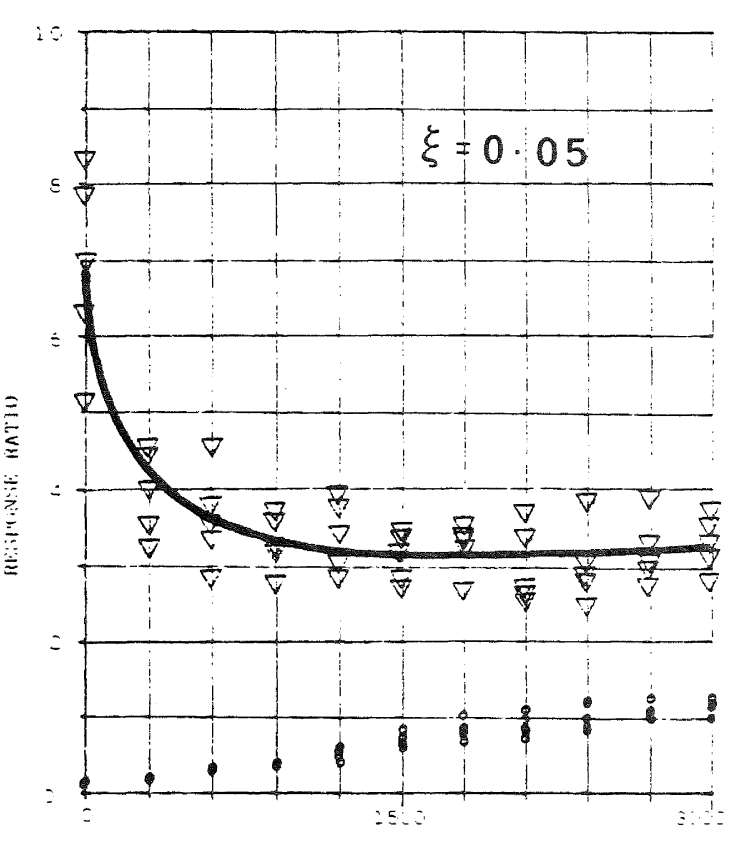

MAXIMUM DAMPER FORCE KN $\left.\begin{array}{l}k_{p} \\ k_{p}\end{array}\right\}$

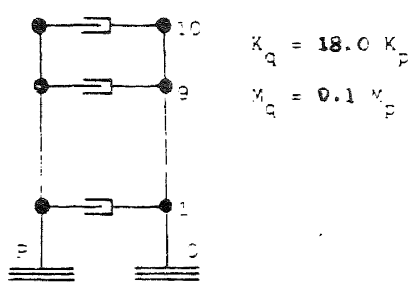

FIGURE 5

BASE SHEAR RESPONSE TO FIVE

EARTHQUAKES. $\quad \xi$ =structure damping 
This effectively means that it becomes possible to introduce a shear wall system without paying the penalty of increased base shear. Furthermore the distribution of shears in the damped structure places a considerably reduced proportion of shear on the shear wall as compared with the rigidly connected structure. Table 2 shows the distribution of base shear between the $P$ and $Q$ (shear wall) structures for the five earthquake records.

It will be seen from Table 2 that in the damped structure the $\mathrm{P}$ structure shears are substantially less than those of the free standing $P$ structure.

As an example, using a maximum damper force at each level of 0,24 Newtons/Kg of floor mass the following mean results for the five earthquakes were obtained:

1. Base shear for the flexible structure alone

$1180 \mathrm{kN}$

2. Base shear for the rigidly connected stiff + flexible structure

$3020 \mathrm{kN}$

3. Base shear for the combined structure + damping

Apportioning (3) between the stiff and flexible elements:

4. Base shear for the flexible structure

$700 \mathrm{kN}$

5. Base shear for the stiff structure

$520 \mathrm{kN}$

The benefits of the damped system are not limited to a straightforward elastic response comparison of base shears. A rigidly connected shear wall structure suffers from two important disadvantages:

* The shear walls take a large proportion of the shear, in consequence of which they are liable to overturning.

* Shear walls tend to be brittle elements so that failure occurs before the more ductile beam and column of the structure. This is borne out by damage studies.

The reduction of forces on the shear wall section produced by the introduction of damping solves both these problems. Furthermore by adjusting the amount of damping the structural engineer has a range of options at his disposal.

\section{CONCLUSIONS:}

The study carried out suggests considerable potential in design application for this system.

One of the advantages of the system of added damping is that it is not dependent on fine tuning of structural properties in any way. The only way in which the performance of the dampers is reduced is when the modes of the two structures coincide, an almost infinitely remote possibility if the mass and stiffness matrices are of different proportions.

One reservation about the configuration which uses dampers at each floor level is that very little energy is absorbed at the lower levels where the relative displacements are small. It seems probable that considerably more efficient arrangements can be achieved.

\section{REFERENCES :}

Anon, "Dampers blunt the wind's force on tall buildings", Architectural Record, September 1971 .

D.A. Gasparini, A.D. Chaudhury, L.W. Curry, "Damping of frames with constrained viscoelastic layers", Jnl of the struct Div, ASCE, STl, Jan 1980, 115-131.

J.M. Kelly, R.I. Skinner, A.J. Heine, "Mechanisms of energy absorption in special devices for use in earthquake resistant structures", Bull of N.Z. Soc for Earthquake Eng, V5, No 3, Sept. 1972.

K. Matsushita, M. Izumi, "Application of input controlling mechanisms to structural design of a tall building", Proc. 5th World Conf. on Earthquake Eng, Rome 1973, V2, 2948-2955.

W.H. Robinson, L.R. Greenbank, "An extrusion energy absorber suitable for the protection of structures during an earthquake", Earthquake Eng. \& Struct. Dynamics, V4, 1976, 251-259.

R.I. Skinner, J.M. Kelly, A.J. Heine, "Hysteretic dampers for earthquake resistant structures", Earthquake Eng. \& Struct. Dynamics, V3, 1975, 287-296.

R.I. Skinner, J.L. Beck, G.N. Bycroft, "A practical system for isolating structures from earthquake attack", Earthquake Eng. \& Struct. Dynamics, V3, 1975, 297-309.

E. Zeller, "Dynamic tests on an actual building mounted with a new damper system", Proc 5th World Conf. on Earthquake Eng., V2, Rome 1973, 1517-1520. 


\begin{tabular}{|c|c|c|c|}
\hline \multirow{2}{*}{$\begin{array}{c}\text { EARTHQUAKE } \\
\text { RECORD }\end{array}$} & \multicolumn{3}{|c|}{ BASE SHEAR $\left(\mathrm{kN} \times 10^{4}\right)$} \\
\cline { 2 - 4 } & $\begin{array}{c}\text { P STRUCTURE } \\
\text { ALONE }\end{array}$ & $\begin{array}{c}\text { P }+ \text { Q RIGIDLY } \\
\text { CONNECTED }\end{array}$ & $\begin{array}{c}\text { P }+\mathrm{Q} \text { WITH } \\
300 \mathrm{kN} \text { DAMPING }\end{array}$ \\
\hline 1 & 1.4 & 3.3 & 1.4 \\
\hline 2 & 1.0 & 2.9 & 1.1 \\
\hline 3 & 1.2 & 2.9 & 1.2 \\
\hline 4 & 0.9 & 2.7 & 1.2 \\
\hline 5 & 1.4 & 3.3 & 1.2 \\
\hline
\end{tabular}

TABLE 1 COMPARISON OF BASE SHEARS

\begin{tabular}{|c|c|c|}
\hline \multirow{2}{*}{$\begin{array}{c}\text { EARTHQUAKE } \\
\text { RECORD }\end{array}$} & BASE SHEAR $\left(\mathrm{kN} \times 10^{4}\right)$ \\
\cline { 2 - 3 } & P STRUCTURE & Q STRUCTURE \\
\hline 1 & 0.9 & 0.5 \\
\hline 2 & 0.6 & 0.5 \\
\hline 3 & 0.7 & 0.5 \\
\hline 4 & 0.7 & 0.5 \\
\hline 5 & 0.6 & 0.6 \\
\hline
\end{tabular}

TABLE 2 BASE SHEARS FOR THE DAMPED $P+Q$ STRUCTURE

Shear wall stiffness ratio, $F=18.0$

Maximum damper force $=300 \mathrm{kN}$

Structure damping $=0.05$ 